\title{
Study on the Transformation of Finance Accountants in Colleges and Universities
}

\author{
Xiufen Bao \\ Finance Department, Hubei University of Science and Technology, Xianning, Hubei, 437000
}

Keywords: colleges and universities; financial accountant; transformation; management-oriented accountant

\begin{abstract}
With the development of information technology, artificial intelligence technology and society, it is extremely urgent to transformation for the financial accountants in colleges and universities to transform. In order to better keep with the development of the time and strengthen the competitiveness of colleges and universities, the paper focuses on the problems of financial personnel themselves and higher requirements imposed on them caused by information development. Through improving appraisal mechanism and the management of accounting system, their ideological transformation has been achieved and comprehensive quality has been enhanced. The research in this paper provides strong support and reference for the solution of the problems in the transformation of finance accountants in the future.
\end{abstract}

\section{Introduction}

Nowadays, information technology and artificial intelligence technology have enjoyed rapid progress, which are widely applied in every sectors of society. They should be the first to be introduced into the work of finance accounting, as it is a profession closely relating with data information. Information technology can not only replace accounting and the task of typing-in original voucher, but also the task of traditional artificial analysis, selection and collection, which provides accurate and thorough financial information for administrators and decision makers. At present, in financial management in colleges and universities, information technologies have been introduced, thus liberating financial accountants from tedious work. Meanwhile, the demand for accountants in colleges and universities has greatly reduced. On November 7, 2017, the Ministry of Finance published information on the cancellation of the accounting certificate, which indicates that the development of information technology has greatly lowered the threshold for financial personnel and more people can take on related financial work. This also means that more people will involve in accounting, which poses a great challenge for financial personnel in colleges and universities.

In addition, with the development of society and economy, the management system in colleges and universities is reforming and the demands on financial personnel are also being raising. At present, the administrators in colleges and universities require financial personnel not only to undertake the task of reimbursement and provide data, but also to be able to analyze the overall future development of schools from the perspective of economy based on financial data, provide valuable information to support decision and risk management. In the meantime, the administrators in colleges require financial accountants to take on more work and provide reliable information in the aspects of strategic planning, risk management, financing and investment decision, performance appraisal, comprehensive budge and cost management.

To sum up, the financial accountants in colleges and universities are not only face fierce competition from outside, but also need to enhance their own abilities and transform their roles from financial accountants into management-oriented accountants. This is an irresistible trend and the requirement of the time.

\section{The Significance of the Transformation for Financial Accountants In Colleges and Universities}

With the rising of intellectual technology and big data, the existing financial accountants cannot meet the needs of the development of colleges and universities, which causes the appearance of 
management-oriented accountants. They can sort out and analyze basic financial data from the aspect of strategic planning, risk management, financing and investment decision, performance appraisal, comprehensive budge and cost management to draw a conclusion, thus providing the basis for the decision-making of the administrators in colleges and universities.

\subsection{Keeping with the development of science \& technology and the time.}

In the era of information, the data of accounting can also be rapidly classified and analyzed by intelligent technology, which brings a lot of convenience to accountants and greatly changes the focus of accountants' work. From accounting basic data to focusing on data analysis, accountants are required to possess strong professional level. Therefore, the transformation from financial accountants to management-oriented accountants adapts to the development of information and meets the need of sustainable competitive development among colleges and universities. The work of management-oriented accountants focuses on decision-making management, performance appraisal, risk prevention, cost control, etc. They should stand on the future to predict future development trend and plan development strategy in an appropriate way, thus enabling themselves in an undefeated position in the development of times.

\subsection{Enhancing the overall competitiveness for the development of colleges and universities}

Colleges and universities are the cradle of cultivating national talents. Facing with current fierce competition, companies need to take more efforts and energy to win in the market. Accountant, as an important member of business managers, should plays the greatest role. It requires them to not only be skillful in the accounting and follow-up analysis, but also provide ex ante forecasting and in-process control for companies through interpreting information in order to promote the reform of the management style and system in colleges and universities[1].

\subsection{Improving the comprehensive quality of financial personnel}

With the advent of the era of information, the traditional accounting can be done by computers, which frees financial personnel from tedious accounting work. Meanwhile, higher requirements are also put forward. Therefore, financial personnel should update ideas in order to adapt to social development and change their focus of work from documents-making and accounting to the analysis on financial data, which requires them to pay close attention to and know the information on some latest policies, laws and regulations, risk prevention and control, strategic planning and decision-making management. Hence, financial personnel should improve their abilities in all aspects, learn more knowledge and learn from failures, and enhance their comprehensive quality.

\subsection{Promoting teaching reform of financial and accounting major in colleges and universities}

In the time of big data, many accounting-related tasks can be done by computer; it results to reduce the demand for accounting posts in society. Thus, it is imperative for colleges and universities to reform teaching plan, adjust education contents, reduce related curriculum and add practice of management accounting for students majoring in accounting and improve their ability in processing computer data. In addition, students should practice and study in companies and combine theories and practice, which can make them know accounting system. Teachers can conduct research projects with students in order to cultivate versatile talents.

\section{The Problems in the Transformation of Financial Personnel in Colleges and Universities}

Although it is an irresistible trend for colleges and universities to transform their financial personnel from financial accountants into management-oriented accountants, such transformation encounters many problems, which are reflected in the following aspects:

\subsection{The problems in financial personnel}

After the information on the cancellation of accounting certificate published by Ministry of Finance on November 7, 2017, the accounting personnel are in panic. Such policy means that social demand has saturated and basic accountants are oversupply. Meanwhile, after the cancellation of accounting certificate, more people will engage in this industry. At present, financial accountants in colleges and 
universities are mainly occupied in accounting and gain no opportunities to be trained in other aspects, only skillful in one aspect, which cannot make them adapt to the development and requirement of the time. Besides that, long-time work on sorting out basic data makes their thought rigid. Their knowledge is very limited. They are not good at embracing new things. Some old and experienced accountants with limited energies who have worked in this position for over 20 years are face with huge challenge mentally and physically if they are required to transform from financial accountants into management-oriented accountants. Therefore, all of these have increased the difficulty of transformation for modern accountants.

\subsection{Higher requirements imposed on financial personnel by informatization}

Big data is not only a concept but also a technology. In today's economic development, big data has become an indispensible part of our life. It can provide more rapid, accurate and scientific support and lay a solid foundation for implementation and completion of work, especially in processing complex problems [2]. Under such circumstance, more high-end accounting management talents are needed. And financial personnel are also face with opportunities and challenge, but it still requires improving accountants' knowledge on informatization.

\subsection{Incomplete incentive appraisal mechanism in colleges and universities.}

The reform of accounting system by government also poses new requirements on financial work in colleges and universities. If the system of selecting talents and promoting assessment is incomplete, then it is hard to motivate financial accountants and performance appraisal cannot be guaranteed, thus impacting the realization of their long-term development goals.

\subsection{Incomplete system of management accounting in colleges and universities}

Management accounting plays an important role in improving the management of colleges and universities, enhancing core competitiveness, saving operational cost and preventing financial risks, but its role is still not given its full play in financial management in colleges and universities [3]. First, the budget management in colleges and universities is against the law of sustainable development [4]. In accordance with the principles of balance of payment of national fiscal appropriation, the budget in colleges and universities cannot reflect development strategy and fund demand of colleges and universities without budget management concept in real sense, which is unfavorable to the stability and sustainable development of colleges and universities. Second, the data about financial accounting are only recorded in statements without much analysis on them. Conducting ex ante forecasting from the aspect of strategic planning, cost control, risks prevention, performance appraisal, etc. makes the decision made by administrators in colleges and universities not enough scientific and objective. Last, incomplete system of management accounting cannot reflect financial condition truthfully and grasp advanced information timely, which are unfavorable to the overall development and competitiveness of schools.

\section{Strategies for the Transformation of Financial Accountants in Colleges and Universities}

In response to the problems in the transformation from financial accountants to management-oriented accountants in colleges and universities, we can start from the following aspects:

\subsection{It should change the ideology of financial personnel}

The times are changing, so are people. In today' rapid development era, it is an eternal truth that not to advance is to drop back. Therefore, we should be aware of its seriousness. It is an inevitable trend to encounter opportunities and challenge in moving toward management-oriented accountants. Financial accountants cannot take the so-called "comfortable" attitude to do the work, which is not suited to the development of the time any more. We need to adapt to the law of development of the time, keep up with the pace at which the state encourage colleges and universities to reform, start with our mentality to change the way of thinking in our work, learn new knowledge, update management concept, endeavor to innovate, learn from and communicate with advanced colleges and universities and think a lot, thus making the contribution to the development of schools. 


\subsection{It should actively improve professional skills and comprehensive ability of financial personnel}

With the arrival of the age of intelligence, on the one hand, financial personnel can be free from tedious work; on the other hand, higher requirements are imposed on their management accounting ability. Learning basic knowledge cannot meet the need of the development of the time. It requires them to broaden their knowledge structure, constantly improve knowledge reserve, learn management accounting well on the basis of practical experience, and start from the analysis on turnover of capital in colleges and universities to do planning, prevention and monitoring in response to budget, performance, cost management and tax planning. They should learn more, practice a lot and reflect frequently. Through sorting out and analysis by management-oriented accountants, the core significance can be reflected in basic financial data, thus providing the basis for administrators of colleges and universities to make decision.

\subsection{It should build appropriate incentive appraisal mechanism in colleges and universities}

Human resource department should select and cultivate excellent accountants, plan the channel for the promotion of financial personnel and motivate them for the development of the colleges and universities. Financial department should build sound appraisal and incentive mechanism targeting financial personnel, formulate detailed and quantitative appraisal system, issue corresponding incentive measures and set up incentive mechanism combining performance appraisal and performance-related pay in accordance with the characteristics of financial work [4], which can improve management efficiency, optimize resources structure and give full play to internal cultivation mechanism. In addition, it should compete for a post, build and improve rotational mechanism, allocate personnel appropriately, train accountants' comprehensive ability and professional skills and enhance their motivation of transformation.

\subsection{It should build complete management accounting system}

Management accounting refers to using a series of methods to sort out and process data and information provided by financial accountants again in order to coordinate with administrative staff to plan, control and manage various daily business activities and help decision makers to predict and monitor future financial activities in a scientific manner, thus guaranteeing the scientific and objective decision [5]. Financial personnel should combine the development of institutions with future planning and build complete budget management mechanism. Meanwhile, it should make budget, conduct cost management and form performance appraisal for teaching, research, administration and logistics in order to conduct scientific and efficient analysis, select optimal management method, come up with appropriate strategic planning, cost control and risk prevention, adjust to the change of economic development and find out risk factors in operation, thus helping administrators in colleges and universities to make scientific and efficient decision.

\section{Conclusion}

To sum up, in the era of big data with rapid development, accountants in colleges and universities are face with both opportunities and challenge. It is an irresistible trend to transform from financial accountants to management-oriented accountants. Hence, it requires them to change their ideas, constantly learn new knowledge, actively improve their professional level and comprehensive ability, apply management accounting into actual work and provide decision information for the development of colleges and universities. Additionally, it requires colleges and universities to build appropriate human resource management system and promotion mechanism for accountants, plan promotion channels for financial personnel and motive them. Meanwhile, it should set up complete management accounting system in order to make financial management run through each link of planning, strategy, prediction, execution and analysis, thus achieving reasonable allocation of resources and promoting stable and rapid development of colleges and universities. 


\section{References}

[1]. Zhang Xiaocai, Study on the Companies' Demand for Accountants under the Background of the Transformation of Accountants [J]. Economist, 2018(06):84-85

[2]. Li Jie, Reflection on the Transformation from Financial Accountants into Management-oriented Accountants in the Era of Big Data [J]. Financial Accounting Analysis, 2018:58-60

[3]. Liu Chunli, Research on the Transformation of Financial Management in Colleges and Universities from the Perspective of Management Accounting [J]. Business Economy, 2018(06):16-17,156

[4]. Zhai Jiaojiao, Analysis on the Current Situation and Countermeasures of the Construction of Financial Personnel in New Era [J]. Management \& Technology of SME, 2018:52-53

[5]. Wu Jingyu, Research on the Building the System of Management Accounting in Colleges and Universities [J].Accountant, 2018, (13), 6-7 